ORIGINAL ARTICLE

\title{
A cross-sectional study of triallate exposure and neurological health among workers at a pesticide manufacturing and formulating facility
}

\author{
N Sathiakumar, E Delzell, P A MacLennan, M Anne, N L Rosenberg, H Cheng, S L Myers
}

Occup Environ Med 2004;61:936-944. doi: 10.1136/oem.2004.013128

See end of article for authors' affiliations

Correspondence to: Dr N Sathiakumar, Department of

Epidemiology, School of Public Health, 1665 University Blvd, University of Alabama at Birmingham, Alabama, USA; nalini@uab.edu

Accepted 9 May 2004

\begin{abstract}
Aims: To evaluate the relation between an indicator of cumulative exposure to triallate and selected measures of neurological function, including nerve conduction, the prevalence of certain neurological deficits as determined by a medical examination, and vibration perception threshold testing in workers at a pesticide manufacturing plant.

Methods: Subjects were 50 workers with high estimated triallate exposure ("high triallate" group) and 50 workers with no or low triallate exposure ("no/low triallate" group). Industrial hygienists used existing work histories and personal knowledge of plant operations to develop a triallate score. In-person interviews elicited information on past medical history and on occupational and non-occupational exposures. A neurologist carried out nerve conduction tests of the sural and the peroneal nerves, a standardised neurological examination, and vibration sensation testing.

Results: Differences between the high and the no/low triallate groups were minimal for all but one of the six nerve conduction tests, for the prevalence of neurological abnormalities, and for vibration sensation perception. The high triallate group had lower mean sural nerve peak amplitude than the no/low triallate group (11.7 $\vee 15.2 \mu \mathrm{V}, \mathrm{p}=0.03$ ). This difference was reduced when adjusted for other potential risk factors (12.5 v $14.5 \mu \mathrm{V}, p=0.25)$ and was not associated with cumulative triallate score. We also noted several associations between factors other than triallate and nerve conduction measures.

Conclusion: The results were consistent with the absence of an association between triallate and measures of neurological function.
\end{abstract}

T riallate (S-2, 3, 3, trichloroallyl diisopropyl thiocarbamate) is the active ingredient in several preemergent herbicides. Toxicological research has shown neurological abnormalities among rats fed very high repeated doses of triallate. ${ }^{1-3}$ These included axonal and myelin degeneration in the gracilus tract of the spinal cord at 500 ppm; axonal and myelin degeneration in the gracilus tract and in the sural, sciatic, and tibial nerves, and functional behavioural changes at $2000 \mathrm{ppm}$; and behavioural changes associated with axonal degeneration in the brain stem (medial longitudinal fasicilus and the facial motor nerve) at $6000 \mathrm{ppm}$. Decreased body weight gain or a loss in body weight occurred at all dose levels.

The specific regions of the peripheral and central nervous systems affected in rats in high dose studies are present in humans and have similar functions. In humans, axonal degeneration of peripheral nerves in the lower limbs would cause muscle weakness and sensory deficits of lower extremities. Axonal degeneration in the spinal cord, brain stem, and cerebellum would result in disturbances of coordination (eye, extremities), proprioception (awareness of body position in space), vibration sensation, gait, and balance. Degenerated axons in the trigeminal and facial cranial nerves would produce impaired sensation over the face and weakness of facial muscles, respectively.

Neurological health has not been assessed in people who work with triallate. The present study of triallate formulation workers evaluated the relation between neurological function and an indicator of cumulative exposure to triallate, as well as certain personal attributes, lifestyle factors, medical conditions, and occupational exposure to agents other than triallate.

\section{METHODS}

\section{Plant operations}

The study plant opened in 1961 as an anhydrous ammonia storage terminal. Its primary operations have been the manufacture, formulation, and packaging of herbicide ingredients or herbicides and the production of plastics. Current operations include the formulation of triallate, the production and formulation of acetanilide herbicides, and the production of glyphosate.

Triallate is formulated and packaged in annual campaigns that last approximately three months. Liquid formulation of triallate began around 1970, and granular formulation began in 1972. In liquid formulation, triallate is mixed with aromatic solvents (mainly trimethyl benzenes, xylenes, or cumene), emulsifiers, and antifoaming agents in outdoor closed blend tanks. The finished product is packaged in plastic jugs or drummed. In granular formulation, triallate is admixed directly onto clay. Clay granules undergo screening and then are preheated in a closed rotary mixer to remove excess moisture. Triallate is then fine sprayed onto the clay granules, and the granular triallate product is bagged. Formulation was always conducted in closed systems, but packaging evolved over time from manual to automated systems.

Diallate (S-(2,3-dichloroallyl) diisopropyl-thiocarbamate), structurally similar to triallate, was the original thiocarbamate herbicide active ingredient formulated at the plant. Diallate liquid and granular formulation began in 1969 , diminished after 1976, and ceased in 1986, due in part to concerns about its potential carcinogenicity.

\section{Design and study base}

The study was cross-sectional and was designed to determine if there were any chronic neurological effects of cumulative 
Main messages

- The results of this cross-sectional study among workers at a pesticide manufacturing plant were consistent with the absence of an association between an indicator of cumulative exposure to triallate and selected measures of neurological function, including nerve conduction, the prevalence of certain neurological deficits as determined by a medical examination, and vibration perception threshold testing.

exposure to triallate. Eligible subjects were men and women who were hired during or after 1976; had worked for at least one year at the plant; had employee records that contained information on birth date, gender, race, and plant employment dates; had work histories adequate for estimating exposure to triallate; were working at the plant as of 15 December 2000 (the date when study subjects were identified), or were retired, alive as of 15 December 2000, and living within a radius of about 20 miles of the plant; and were not pregnant at the time of testing.

The one year duration of employment criterion was necessary because assignments in triallate formulation and packaging during the annual three month campaigns were not recorded in employees' work histories. We excluded employees who were hired before 1976 because the paucity of information on diallate operations made it difficult to estimate exposure to this agent and because we wished to minimise its potential to confound relations between triallate and neurological function.

Databases developed for previous epidemiological investigations of plant workers ${ }^{4-6}$ contained information on 2781 workers ever employed at the plant from 1961 to 1999. Of these, 349 were eligible, and 2432 were ineligible, due to employment for less than one year $(n=579)$, insufficient work history to determine triallate exposure score $(n=161)$, having been hired before $1976(n=1239)$, being deceased $(\mathrm{n}=39)$, or having separated from employment at the plant during or before $2000(n=414)$.

The 349 eligible subjects had a median age of 41 years and had worked at the plant for a median of 8.0 years as of 1 January 2001; 73\% were hourly, and 34\% had not worked with triallate. The 414 employees who were otherwise eligible but had separated without retiring had a median age of 42 years and had worked at the plant for a median of 3.0 years as of 1 January 2001; 57\% were hourly, and 50\% had not worked with triallate.

\section{Exposure estimation}

To develop a cumulative triallate score for each of the 349 eligible employees, we first identified from the work histories of eligible employees 403 unique calendar year specific combinations of department/location/job title and compiled a job-exposure matrix (JEM). Each department consisted of a group of common processes. Locations were specific areas within a department. Using information on current and past triallate operations and on jobs and tasks within each operation, an industrial hygienist with several years of experience at the plant specified a total of 34 "occupational exposure categories" (OECs), each of which consisted of operations that were similar with regard to work activities and potential exposure to triallate. In some OECs, all job titles had similar exposure potential, whereas in other OECs, exposure potential varied among jobs.

The industrial hygienist assigned a level of potential triallate intensity $($ high $=1.0$, moderate $=0.3, \quad$ low $=0.1$,

\section{Policy implications}

- This study was done at the request of the Pesticide Safety Directorate (PSD) in the UK because of concerns of potential neurological toxicity of triallate.

- The results of this study will provide the regulatory agencies, particularly the PSD, the necessary information to evaluate the registration of this compound.

none $=0$ ) to each $\mathrm{OEC} / \mathrm{job} /$ calendar year combination and specified the appropriate OEC for each department/location/ job/year combination in the JEM. We used this information to assign a triallate intensity level to each combination in the JEM, linked the JEMs to subjects' work histories, and computed each subject's cumulative triallate score. To do this, we multiplied the days spent in each department/ location/job/calendar year combination by the intensity level for that combination and summed over all combinations in the subject's work history. The resulting score is a crude indicator, rather than a quantitative measure, of a subject's actual cumulative triallate exposure.

\section{Subject selection}

From the 349 eligible employees, we selected 50 with the highest triallate scores and 50 with no exposure or low scores. We chose a study size of 100 subjects to enable us to detect a clinically meaningful difference in mean sural nerve amplitude between the exposed and the unexposed groups. Power calculations, based on published data on sural nerve conduction amplitude means, ${ }^{78}$ indicated that a study of 50 exposed and 50 unexposed subjects would have $80 \%$ power to detect a statistically significant $20-25 \%$ difference between the exposed and the unexposed subjects. This is a reasonable estimate based on the wide variation of sural nerve amplitude in normal subjects of about $30-40 \%$ from the mean, making differences between exposed and unexposed subjects to be clinically meaningful beyond $40 \% .^{7-9}$

We ranked all 349 eligible employees according to their cumulative triallate score. To choose the high triallate group, we first specified two subgroups, one consisting of employees hired from 1976 to 1985 and the other consisting of employees hired after 1985, and selected the 25 subjects with the highest triallate scores in each subgroup. We then stratified these subjects by age (20-29, 30-39, 40-49, 50-59) and gender and determined the number in each stratum.

To choose the two no/low triallate groups, we stratified the remaining 299 subjects by hire year (1976-85, after 1985), age, and gender. We ranked all subjects within each of the 16 strata by their cumulative triallate score and within each stratum selected from among those with the lowest scores the same number as in the corresponding stratum of subjects in the high triallate group.

Of the 100 subjects initially selected, 91\% participated. Non-participants included three in the high and six in the no/ low triallate groups. We excluded three participants. One was pregnant (high triallate group, hired after 1985), another terminated before neurological testing began (high triallate group, hired after 1985), and the third subject (high triallate group, hired in 1976 to 1985) had no matching low score subject in the same age group. The latter subject was one of four retirees among the 349 eligible subjects. We selected 12 replacement subjects with the next highest (high triallate group) or next lowest (no/low triallate group) cumulative triallate score within the same year of hire group and age/ gender stratum. 


\section{Interviews}

Plant management informed workers about the study. Subsequent recruitment letters invited subjects to participate in an interview and examination, conducted at an off-site medical office. We obtained written informed consent at the time of the subjects' appointments. Participants were paid $\$ 125$ when they arrived for their appointment, regardless of their decision to participate.

One research assistant, who was not aware of subjects' triallate score, conducted all interviews in person. The questionnaire asked about past medical history, certain non-occupational exposures, and exposures in plant and non-plant jobs. The research assistant obtained information on plant exposures towards the end of the interview, after obtaining information on neurological status and nonoccupational factors. We did not obtain medical records to confirm self reported diagnoses. Data on plant exposures other than triallate were based on self reports.

\section{Tests and examinations}

Nerve conduction tests evaluated the function of sural and peroneal nerves in one lower extremity. The sural nerve conduction test evaluated the sensory component of the sural nerve at the calf to obtain the sural nerve amplitude, the peak-to-peak amplitude, and the velocity. The peroneal nerve test evaluated the motor component of the common peroneal nerve at the ankle and at the fibular neck to obtain the amplitude at the ankle, the amplitude at the fibular neck, and the velocity. A single neurologist (NLR), who did not know subjects' triallate score, conducted all tests using percutaneous stimulation and made paper recordings of all results, using the TECA Synergy notebook (Oxford Instruments Medical, Inc., Hawthorne, NY). Normal values for the nerve conduction measures were taken from standard published norms. ${ }^{7-9}$ Vibration threshold perception testing evaluated the integrity of the gracilus tract. The neurologist performed vibration perception tests on the great toe and index finger on one side of the body by the "two alternative forced choice procedure", ${ }^{10}{ }^{11}$ using the Vibraton II (Physiotemp Instruments, Inc., Cifton, NJ) equipment.

The neurologist assessed each subject's clinical neurological status according to a set of clinical signs. We classified a subject as abnormal if he/she had an abnormality of peripheral nerve function, proprioception, cranial nerve function, or vestibulocerebellar function. We considered each category as abnormal if any one component within that category was abnormal, or normal if all components within that category were normal. For example, we rated proprioception as abnormal if any one of its components (sense of position, passive movement, vibration, or two point discrimination). The neurologist also determined each subject's mental status, weight, height, and blood pressure before the start of the neurological examination and nerve conduction testing. Mental function was assessed using the short test of mental status. ${ }^{12} 13$

\section{Institutional Review Board (IRB)}

The study underwent a full review by the IRB of the University of Alabama at Birmingham.

\section{Analysis}

For the continuous outcome variables, including nerve conduction test and vibrometry values, we used $t$ tests to assess differences in means between the high and no/low triallate groups, without adjusting for potential confounding factors, and we used analysis of covariance to examine differences in means, adjusted for potential confounders. We also compared the means of sural and peroneal nerve conduction test values among four triallate score categories (zero, 15-<525, 525-<3834, and 3834-8728), with cut-points corresponding to tertiles of scores greater than zero among all subjects. We compared the prevalence of neurological abnormalities between the high and the no/low triallate groups using the prevalence odds ratio (POR) with its corresponding 95\% confidence interval (CI). We used exact logistic regression procedures to adjust for other risk factors. We included a potential risk factor other than triallate in a logistic regression model if there was moderate association in either direction (positive or inverse) between the risk factor and the prevalence of a neurological abnormality (that is, POR of $\geqslant 2.0$ or $\leqslant 0.5$ ) and if at least two subjects exposed to the risk factor had an abnormality.

\section{RESULTS}

Of the 100 subjects, 72 were men and 28 were women (table 1). Within period of hire categories, the high and the no/low triallate group were equally distributed by 10 year age category and by gender. All subjects were active employees. The high and no/low triallate groups had similar year of hire distributions. The high triallate group had a higher proportion of hourly subjects (94\% v 62\%) and a lower proportion of salaried subjects $(6 \% \vee 38 \%)$ than the no/low triallate group. The median duration of employment was 13.1 years for the high and 9.0 years for the no/low triallate group. Subjects hired in 1976-85 were older (median 44 years) and tended to be long term workers (median duration of employment, 20.3 years; range 7.4-24), than subjects hired after 1985 who were relatively younger (median 35 years), shorter term workers (median 3.1 years; range $1.0-11$ ). The median cumulative triallate score was 0 for the no/low score group and 2576 for the high score group. The median score of the high triallate group hired in 1976-85 was nearly seven times higher than that of the high triallate group hired after 1985 (4824v 714). One subject in the no/low triallate group hired in 1976-85 had a score that overlapped with those of the high triallate group hired after 1985 .

\section{Nerve conduction tests}

Analyses of nerve conduction tests excluded six test values of three subjects in the high triallate group. Three sural nerve and one peroneal nerve amplitude at the fibular neck test results of one subject were unsatisfactory because the subject was obese (body mass index (BMI), 48.1) and had oedema over both the stimulation and the recording sites. Two subjects had an abnormal result for peroneal nerve amplitude at the ankle but had concomitant normal peroneal nerve amplitude at the fibular neck. The finding of proximal stimulation at the fibular head resulting in larger (rather than smaller) amplitude than distal stimulation suggests that the integrity of the peroneal nerve is intact throughout its length and that the lower amplitude obtained with ankle stimulation is due to either a technical problem or an anomalous course of the nerve. Thus, for these two subjects, we retained the test values for the peroneal nerve amplitude at the fibular neck.

The high triallate group had a statistically significantly lower mean sural nerve peak amplitude than the no/low triallate group $(11.7 \mu \mathrm{V} \vee 15.2 \mu \mathrm{V}, \mathrm{p}=0.03)$ (table 2 ). A difference occurred both among subjects hired in 1976-85 ( $11.8 \mu \mathrm{V} v 14.4 \mu \mathrm{V}, \mathrm{p}=0.31$ ) and among subjects hired after $1985(11.6 \mu \mathrm{V} v 16.0 \mu \mathrm{V}, \mathrm{p}=0.04)$. For the other two sural nerve tests and for the three peroneal nerve tests, differences between the mean values of the high and the no/low triallate groups were small.

The median age of subjects in the four triallate score groups (zero, 15-<525, 525-<3834, 3834-8728) were 40, 43, 38 , and 43 years, respectively. Subjects in the highest triallate score group tended to have mean and median nerve conduction values that were less than those of subjects in 
Table 1 Number of subjects by triallate group and by gender, race, age, and employment characteristics

\begin{tabular}{|c|c|c|c|c|c|c|}
\hline \multirow[b]{2}{*}{ Characteristic } & \multicolumn{2}{|l|}{ All subjects } & \multicolumn{2}{|l|}{ Hired 1976-85 } & \multicolumn{2}{|l|}{ Hired $>1985$} \\
\hline & No/low triallate & High triallate & No/low triallate & High triallate & No/low triallate & High triallate \\
\hline Total & 50 & 50 & 25 & 25 & 25 & 25 \\
\hline \multicolumn{7}{|l|}{ Gender } \\
\hline Male & 36 & 36 & 17 & 17 & 19 & 19 \\
\hline Female & 14 & 14 & 8 & 8 & 6 & 6 \\
\hline \multicolumn{7}{|l|}{ Race/ethnicity } \\
\hline White & 50 & 47 & 25 & 25 & 25 & 22 \\
\hline Black & 0 & 1 & 0 & 0 & 0 & 1 \\
\hline Hispanic & 0 & 2 & 0 & 0 & 0 & 2 \\
\hline \multicolumn{7}{|c|}{ Age (y) at 1 Jan 2001} \\
\hline $20-29$ & 5 & 5 & 0 & 0 & 5 & 5 \\
\hline $30-39$ & 17 & 17 & 4 & 4 & 13 & 13 \\
\hline $40-49$ & 23 & 23 & 19 & 19 & 4 & 4 \\
\hline $50-59$ & 5 & 5 & 2 & 2 & 3 & 3 \\
\hline Median & 41 & 42 & $4 \overline{4}$ & 43 & 34 & 35 \\
\hline \multicolumn{7}{|l|}{ Payroll classification } \\
\hline Ever hourly & 31 & 47 & 15 & 24 & 16 & 23 \\
\hline Always salaried & 19 & 3 & 10 & 1 & 9 & 2 \\
\hline \multicolumn{7}{|l|}{ Year of hire } \\
\hline 1976-80 & 18 & 20 & 18 & 20 & 0 & 0 \\
\hline $1981-85$ & 7 & 5 & 7 & 5 & 0 & 0 \\
\hline $1986-90$ & 2 & 2 & 0 & 0 & 2 & 2 \\
\hline $1991-95$ & 8 & 12 & 0 & 0 & 8 & 12 \\
\hline $1996+$ & 15 & 11 & 0 & 0 & 15 & 11 \\
\hline \multicolumn{7}{|c|}{ Duration of employment (y) } \\
\hline $1-4$ & 17 & 16 & 0 & 0 & 17 & 16 \\
\hline $5-9$ & 8 & 9 & $2^{*}$ & 0 & 6 & 9 \\
\hline $10-14$ & 3 & 0 & $1^{*}$ & 0 & 2 & 0 \\
\hline $15-19$ & 13 & 7 & 13 & 7 & 0 & 0 \\
\hline $20+$ & 9 & 18 & 9 & 18 & 0 & 0 \\
\hline Median & 9.0 & 13.1 & 19.1 & 22.5 & 2.8 & 4.0 \\
\hline \multicolumn{7}{|c|}{ Cumulative triallate score } \\
\hline 0 & 36 & 0 & 11 & 0 & 25 & 0 \\
\hline $15-<525$ & $14 \dagger$ & 8 & $14 \dagger$ & 0 & 0 & 8 \\
\hline $525-<3834$ & 0 & 21 & 0 & 4 & 0 & 17 \\
\hline $3834-8728$ & 0 & 21 & 0 & 21 & 0 & 0 \\
\hline Range & $0-503+$ & $443-8728$ & $0-503 \dagger$ & $3565-8728$ & $0-0$ & $443-1588$ \\
\hline Median & 0 & 2576 & 24 & 4824 & 0 & 714 \\
\hline
\end{tabular}

the lowest triallate score group, but the differences were small, and there was no consistent trend of decreasing mean nerve conduction test values with increasing score (table 3). Adjustment for age reduced the differences in the mean nerve conduction values between the highest and lowest triallate score groups. For example, without adjusting for age, the highest triallate score group had a mean sural nerve peak amplitude that was $2.8 \mu \mathrm{V}$ lower than the mean sural nerve peak amplitude in the lowest triallate score group. Adjustment for age diminished this difference to $1.8 \mu \mathrm{V}$.

Factors other than triallate that were associated inversely with mean sural nerve peak amplitude were cervical disc disorder, back injury, and self reported exposure to plant herbicides other than triallate (table 4). The difference in mean sural nerve peak amplitude between the no/low and the high triallate groups was reduced in magnitude when adjusted for these three factors (no/low triallate, $14.5 \mu \mathrm{V}$; high triallate, $12.5 \mu \mathrm{V} ; \mathrm{p}=0.25$ ). Multivariable modelling indicated that sural nerve peak amplitude was not associated with triallate scores treated dichotomously (no/low, high) ( $\beta$ coefficient $=+0.00, p=0.93$ ) or as a continuous variable ( $\beta$ coefficient $=-0.00, p=0.55)$. Triallate scores also were not associated with any other set of nerve conduction test values.

Analysis of mean values of other nerve conduction tests (table 4) found that sural nerve peak-to-peak amplitude was lower in heavier (BMI $\geqslant 30 \mathrm{~kg}$ weight $/ \mathrm{m}^{2}$ height) than in lighter (BMI $<30 \mathrm{~kg} / \mathrm{m}^{2}$ ) subjects and in subjects exposed to solvents in jobs prior to employment at the plant. Peroneal nerve amplitude at the ankle was lower in subjects with a family history of neurological disease, a high alcohol consumption, and self reported exposure to herbicides other than triallate at the plant than in subjects without each of these attributes. Peroneal nerve amplitude at the fibular neck was lower in subjects with a family history of neurological disease and exposure to herbicides other than triallate than in subjects without each of these attributes. Peroneal nerve amplitude at the fibular neck was higher in subjects with a history of fracture compared to those without a history of fracture. Peroneal nerve velocity was lower in subjects over 40 years of age and in smokers compared to non-smokers.

\section{Neurological examination}

Ten subjects had an abnormality identified by the neurologist's examination. Six of the cases were in the high triallate group, and four in the no/low triallate group. The six cases in the high triallate group had: (1) sensorineural type of hearing loss, right ear (onset unknown) and left facial paralysis following Bell's palsy (onset, one year before examination); (2) sensorineural type of hearing loss, right ear, present since childhood; (3) mild conductive type of hearing loss, left ear (onset unknown); (4) mild conductive type of hearing loss, left ear (onset unknown); (5) tremors in both upper extremities, present since childhood; and (6) radiculopathy of the first sacral segment following back injury resulting in lumbar disc prolapse, present since 1993. The four cases in the no/low triallate group had: (1) peripheral neuropathy (onset unknown); (2) peripheral neuropathy, multiple deficits after sciatica diagnosed in 1980; (3) loss of vibration sensation in lower extremity (onset unknown); and (4) tremor in left upper extremity (onset unknown). 
Table 2 Nerve conduction test results by triallate group

\begin{tabular}{|c|c|c|c|c|c|c|c|c|c|}
\hline \multirow[b]{2}{*}{ Nerve conduction test values } & \multicolumn{3}{|l|}{ All subjects } & \multicolumn{3}{|c|}{ Hired 1976-85 } & \multicolumn{3}{|l|}{ Hired $>1985$} \\
\hline & $\begin{array}{l}\text { No/low } \\
\text { triallate }\end{array}$ & $\begin{array}{l}\text { High } \\
\text { triallate }\end{array}$ & $\mathbf{p}^{*}$ & $\begin{array}{l}\text { No/low } \\
\text { triallate }\end{array}$ & $\begin{array}{l}\text { High } \\
\text { triallate }\end{array}$ & $\mathbf{p}^{*}$ & $\begin{array}{l}\text { No/low } \\
\text { triallate }\end{array}$ & $\begin{array}{l}\text { High } \\
\text { triallate }\end{array}$ & $\mathbf{p}^{*}$ \\
\hline \multicolumn{10}{|c|}{ Sural nerve peak amplitude $(\mu \mathrm{V})$} \\
\hline $\mathrm{n}$ tested $\neq$ & 50 & 49 & & 25 & 24 & & 25 & 25 & \\
\hline Range & $3.2-38.7$ & $0-47.9$ & & $3.2-38.7$ & $4.0-47.9$ & & $4.2-31.9$ & $0.0-27.7$ & \\
\hline Median & 11.6 & 10.0 & & 11.2 & 9.8 & & 14.7 & 10.9 & \\
\hline Mean (SD) & $15.2(8.4)$ & $11.7(7.3)$ & 0.03 & $14.4(8.8)$ & $11.8(8.8)$ & 0.31 & $16.0(8.2)$ & $11.6(5.8)$ & 0.04 \\
\hline Mean, adjusted $\dagger$ & 15.1 & 11.8 & 0.04 & 13.7 & 12.5 & 0.65 & 15.6 & 12.0 & 0.07 \\
\hline \multicolumn{10}{|c|}{ Sural nerve peak-to-peak amplitude $(\mu \mathrm{V})$} \\
\hline $\mathrm{n}$ testedt & 50 & 49 & & 25 & 24 & & 25 & 25 & \\
\hline Range & $3.9-47.7$ & $0-104.3$ & & $3.9-34.4$ & $4.7-104.3$ & & $4.5-47.7$ & $0.0-41.3$ & \\
\hline Median & 11.8 & 11.9 & & 11.2 & 12.0 & & 15.1 & 11.8 & \\
\hline Mean (SD) & $16.2(10.2)$ & $15.1(15.0)$ & 0.66 & $14.0(8.9)$ & $15.4(19.4)$ & 0.76 & $18.4(11.2)$ & $14.8(9.3)$ & 0.22 \\
\hline Mean, adjusted $\dagger$ & 16.2 & 15.1 & 0.69 & 12.9 & 16.6 & 0.39 & 18.1 & 15.1 & 0.33 \\
\hline \multicolumn{10}{|l|}{ Sural nerve velocity $(\mu \mathrm{V})$} \\
\hline $\mathrm{n}$ tested $\ddagger$ & 50 & 49 & & 25 & 24 & & 25 & 25 & \\
\hline Range & $35.4-59.6$ & $0.0-66.7$ & & $35.4-59.6$ & $33.3-62.2$ & & $39.4-58.3$ & $0.0-66.7$ & \\
\hline Median & 49.1 & 49.1 & & 49.1 & 49.6 & & 49.1 & 48.3 & \\
\hline Mean (SD) & $48.9(5.2)$ & $48.2(9.3)$ & 0.68 & $48.5(5.7)$ & $49.1(6.6)$ & 0.71 & $49.2(4.6)$ & $47.4(11.4)$ & 0.45 \\
\hline Mean, adjusted $\dagger$ & 48.9 & 48.2 & 0.62 & 48.8 & 48.9 & 0.95 & 48.8 & 47.8 & 0.68 \\
\hline \multicolumn{10}{|c|}{ Peroneal nerve amplitude, ankle (mV) } \\
\hline $\mathrm{n}$ tested§ & 50 & 48 & & 25 & 23 & & 25 & 25 & \\
\hline Range & $1.1-10.5$ & $0.2-11.6$ & & $1.1-10.2$ & $0.2-11.6$ & & $1.2-10.5$ & $0.5-9.9$ & \\
\hline Median & 4.6 & 4.2 & & 3.9 & 4.2 & & 4.8 & 4.2 & \\
\hline Mean (SD) & $4.8(2.3)$ & $4.6(2.6)$ & 0.78 & $4.8(2.5)$ & $4.6(2.7)$ & 0.80 & $4.8(2.1)$ & $4.7(2.6)$ & 0.90 \\
\hline Mean, adjusted $\dagger$ & 4.8 & 4.6 & 0.78 & 4.8 & 4.6 & 0.74 & 4.7 & 4.7 & 0.99 \\
\hline \multicolumn{10}{|c|}{ Peroneal nerve amplitude, fibular neck (mV) } \\
\hline $\mathrm{n}$ tested $\uparrow$ & 50 & 49 & & 25 & 24 & & 25 & 25 & \\
\hline Range & $0.5-9.4$ & $0.4-11.6$ & & $0.5-9.4$ & $0.4-11.6$ & & $1.7-8.1$ & $0.6-9.1$ & \\
\hline Median & 4.1 & 4.1 & & 4.3 & 4.1 & & 3.7 & 4.4 & \\
\hline Mean (SD) & $4.5(2.1)$ & $4.5(2.5)$ & 0.98 & $4.6(2.2)$ & $4.6(2.7)$ & 0.94 & 4.5 (1.9) & $4.5(2.3)$ & 0.96 \\
\hline Mean, adjusted $\dagger$ & 4.5 & 4.5 & 0.98 & 4.6 & 4.6 & 0.99 & 4.4 & 4.5 & 0.85 \\
\hline \multicolumn{10}{|l|}{ Peroneal nerve velocity $(\mathrm{m} / \mathrm{s})$} \\
\hline $\mathrm{n}$ tested & 50 & 50 & & 25 & 25 & & 25 & 25 & \\
\hline Range & $38.7-55.6$ & $36.5-56.1$ & & $38.7-53.9$ & $39.2-56.1$ & & $40.3-55.6$ & $36.5-53.3$ & \\
\hline Median & 48.2 & 48.3 & & 47.2 & 48.1 & & 48.5 & 48.4 & \\
\hline Mean (SD) & $47.9(4.1)$ & $47.9(4.1)$ & 0.95 & $46.8(4.2)$ & $48.0(4.3)$ & 0.29 & $49.1(3.7)$ & $47.7(3.9)$ & 0.20 \\
\hline Mean, adjusted $\dagger$ & 47.9 & 47.8 & 0.87 & 47.2 & 47.6 & 0.73 & 48.6 & 48.1 & 0.52 \\
\hline
\end{tabular}

*F test comparing the adjusted mean of the high triallate group with the adjusted mean of the no/low triallate group.

†Adjusted for age, gender, and height using analysis of covariance.

$\ddagger$ One subject's sural nerve test results excluded because of technical problems.

$\S$ Two subjects excluded because of technical problems.

-One subject excluded because of technical problems.

The crude POR was 1.6 (CI 0.4 to 5.9) for any abnormality (data not presented in a table). Ten risk factors qualified for inclusion in multivariable analysis: height, urinary tract infection, cervical disk disorder, back injury, smoking, alcohol use, recreational drug use, lead used in hobby, plant herbicides other than triallate, and plant industrial adhesives. Models that included triallate and one of each of these risk factors indicated that height, urinary tract infection, cervical disk disorder, recreational drugs, and alcohol use were weakly to moderately associated with neurological abnormality but had no impact on the POR for triallate. Adjustment for each of the other five factors (smoking, plant industrial adhesives, lead used in hobbies, plant herbicides other than triallate, and back injury) yielded a triallate POR that was slightly lower than the crude POR. In a multivariable model that included these five variables and triallate (high $v$ low), the POR was 0.6 (CI 0.1 to 4.1 ) for triallate, 6.1 (CI 0.9 to 74.7) for smoking, 2.6 (CI 0.3 to 17.0) for plant industrial adhesives, 5.0 (CI 0.7 to 40.3 for lead used in hobbies), 1.6 (CI 0.2 to 79.3 ) for plant herbicides, and 1.6 (CI 0.2 to 11.7) for back injury. Results for triallate were similar when we omitted back injury from the model.

\section{Vibration perception threshold}

The high and the no/low triallate groups had similar median and mean vibration perception threshold values in both the great toe and the finger (table 5). Only one subject, in the no/ low triallate group, had a marked reduction in vibration perception threshold, and this abnormality was limited to the great toe, with no overt signs of peripheral neuropathy.

\section{DISCUSSION}

\section{Nerve conduction differences}

Differences between the high and the no/low triallate groups were minimal for five of the six nerve conduction tests. The high triallate group had a lower mean sural nerve peak amplitude than the no/low triallate group, but several observations suggest that this difference was not due to triallate exposure. Adjustment for other potential risk factors reduced the magnitude of the association. There was no consistent trend of decreasing mean nerve conduction values with increasing triallate scores. The difference was concentrated in subjects hired after 1985. The high triallate subjects in this subgroup were relatively short term workers with a median cumulative triallate score that was about one 
Table 3 Nerve conduction test results according to four triallate score groups

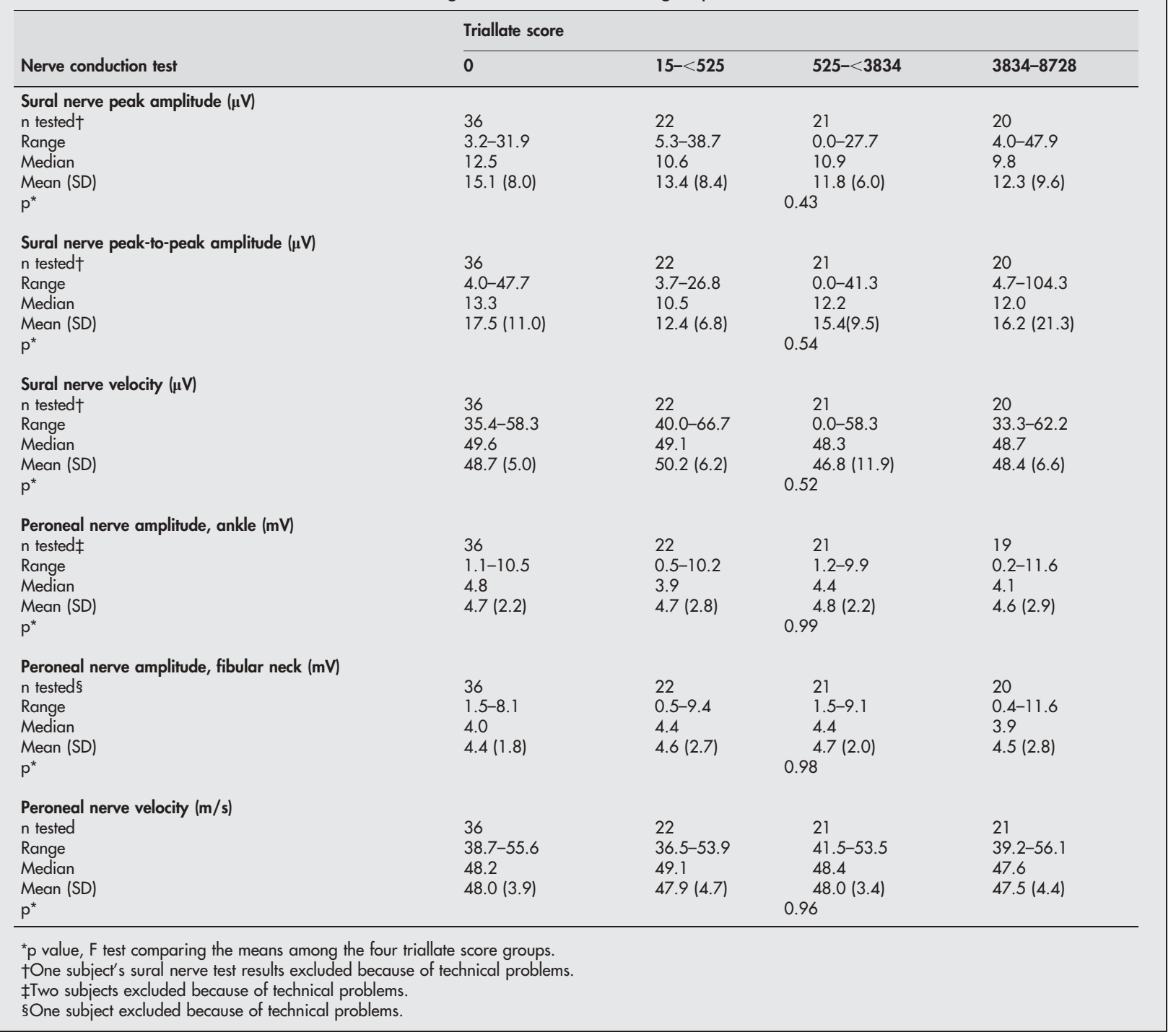

seventh that of the median score of the high triallate group hired during 1976-85.

Investigations of healthy, neurologically normal adults have shown that the lowest sural nerve peak amplitude is 30$40 \%$ below the average amplitude of the group studied, indicating a wide variation in normal subjects. ${ }^{7-9}$ The mean sural nerve peak amplitude of the high triallate group $(11.7 \mu \mathrm{V})$ falls within the range of 5.0-29.0 $\mu \mathrm{V}$ reported for mean sural nerve peak amplitude among unexposed subjects in other occupational epidemiological studies. ${ }^{14-23}$

We found no large or statistically significant differences in other nerve conduction measures between the high and the no/low triallate groups. The high triallate group's mean sural nerve peak-to-peak amplitude and velocity and peroneal nerve conduction values were within the ranges reported for unexposed subjects in other occupational epidemiological studies. ${ }^{14-23}$

We noted several associations between factors other than triallate and nerve conduction measures. Sural nerve peak amplitude was inversely associated with cervical disk disorder, back injury and exposure to plant herbicides other than triallate. To our knowledge, no other study has reported a relation between sural nerve peak amplitude and cervical disk disorder or previous back injury. We did not evaluate exposure to specific herbicides other than triallate at the workplace, and thus, it was not possible to attribute the observed association to any particular agent.

Our observation of an inverse association between BMI and sural nerve peak-to-peak amplitude adjusting for age, gender, and height is consistent with the results reported by Buschbacher. ${ }^{24}$ We found that a family history of neurological disease was inversely associated with peroneal nerve amplitude at the ankle and fibular neck. Berciano et al evaluated 99 subjects who were at risk for hereditary motor and sensory neuropathy types I and II and found that marked reduction in motor nerve conduction was present early in life (2nd decade)..$^{25}$ We also noted age and smoking to be inversely associated with peroneal nerve velocity. Moen et al reported that sural nerve amplitude, peroneal nerve amplitude, and peroneal nerve velocity decreased with increasing age. ${ }^{18}$ Dyck et al reported an inverse association between sural nerve amplitude and age but found no association between smoking and nerve conduction velocity. ${ }^{26}$ On the other hand, Husstedt et al reported that smoking was associated with a decrease in nerve conduction amplitude and velocity. ${ }^{27}$ Our findings of a higher mean sural nerve peak-to-peak amplitude among subjects with solvent exposure and increased peroneal nerve amplitude at the ankle with a history of 
Table 4 Mean (standard deviation) nerve conduction test results for subjects exposed to a potential risk factor compared to subjects unexposed; risk factors with at least one statistically significant difference†

\begin{tabular}{|c|c|c|c|c|c|c|c|}
\hline \multirow[b]{2}{*}{ Risk factor } & \multirow[b]{2}{*}{$\mathbf{n}$} & \multicolumn{3}{|c|}{ Sural nerve testsł } & \multicolumn{3}{|c|}{ Peroneal nerve tests $\S$} \\
\hline & & PA & PPA & VEL & AA & AFN & VEL \\
\hline \multicolumn{8}{|c|}{ Triallate group } \\
\hline No/low & 50 & $15.2(8.4)$ & $16.2(10.2)$ & $48.9(5.2)$ & $4.8(2.3)$ & $4.5(2.1)$ & $47.9(4.1)$ \\
\hline High & 50 & $11.7(7.3)^{*}$ & $15.0(15.0)$ & $48.2(9.0)$ & $4.6(2.6)$ & $4.5(2.5)$ & $47.9(4.1)$ \\
\hline \multicolumn{8}{|c|}{ Personal attributes } \\
\hline \multicolumn{8}{|c|}{ Age (y) } \\
\hline$<40$ & 44 & $14.7(7.5)$ & $17.1(10.6)$ & $47.8(9.0)$ & $5.0(2.6)$ & $4.9(2.3)$ & $49.3(3.3)$ \\
\hline$\geqslant 40$ & 55 & $12.5(8.5)$ & $14.5(14.3)$ & $49.2(6.0)$ & $4.5(2.3)$ & $4.2(2.2)$ & $46.8(4.3)^{\prime}$ \\
\hline \multicolumn{8}{|l|}{ BMI $\left(\mathrm{kg} / \mathrm{m}^{2}\right)$} \\
\hline$<30$ & 53 & $15.4(8.0)$ & $18.4(10.1)$ & $49.4(5.1)$ & $4.7(2.3)$ & $4.6(2.2)$ & $48.2(4.1)$ \\
\hline$\geqslant 30$ & 45 & $11.2(7.8)$ & $12.4(12.5)^{*}$ & $47.6(9.6)$ & $4.7(2.6)$ & $4.5(2.3)$ & $47.5(4.0)$ \\
\hline \multicolumn{8}{|c|}{ Family history of neurological disease } \\
\hline No & 85 & $13.7(8.4)$ & $15.6(13.1)$ & $48.2(7.6)$ & $5.0(2.5)$ & $4.7(2.3)$ & $47.6(4.2)$ \\
\hline Yes & 15 & $12.3(6.2)$ & $16.1(10.8)$ & $50.3(6.5)$ & $3.2(1.2)^{*}$ & $3.4(1.6)^{*}$ & $49.3(3.0)$ \\
\hline \multicolumn{8}{|c|}{ Medical history } \\
\hline \multicolumn{8}{|c|}{ Cervical disk disorder } \\
\hline No & 90 & $13.9(8.3)$ & $16.1(13.1)$ & $48.8(7.7)$ & $4.7(2.5)$ & $4.5(2.3)$ & $48.1(4.0)$ \\
\hline Yes & 10 & $9.4(4.5)^{*}$ & $11.4(8.4)$ & $46.4(4.5)$ & $5.1(2.1)$ & $4.8(1.8)$ & $46.2(4.3)$ \\
\hline \multicolumn{8}{|l|}{ Back injury } \\
\hline No & 82 & $14.1(8.6)$ & $16.5(13.5)$ & $48.4(8.1)$ & $4.8(2.5)$ & $4.6(2.2)$ & $48.0(4.1)$ \\
\hline Yes & 18 & $10.5(4.2)^{*}$ & $12.0(7.8)$ & $49.2(3.9)$ & $4.4(2.5)$ & $4.3(2.5)$ & $47.6(3.9)$ \\
\hline \multicolumn{8}{|l|}{ Fracture } \\
\hline No & 78 & $13.1(7.7)$ & $14.4(9.1)$ & $48.9(7.8)$ & $4.5(2.4)$ & $4.3(2.2)$ & $47.8(4.2)$ \\
\hline Yes & 22 & $14.8(9.3)$ & $20.0(20.9)$ & $47.3(6.0)$ & $5.4(2.5)$ & $5.4(2.4)^{*}$ & $48.2(3.8)$ \\
\hline \multicolumn{8}{|c|}{ Non-occupational exposures } \\
\hline \multicolumn{8}{|c|}{ Smoking } \\
\hline Never & 51 & $14.5(7.7)$ & $16.3(9.3)$ & $49.6(6.0)$ & $4.9(2.5)$ & $4.8(2.3)$ & 48.7 (3.9) \\
\hline Ever & 49 & $12.4(8.4)$ & $15.0(15.7)$ & $47.4(8.7)$ & $4.5(2.4)$ & $4.3(2.2)$ & $47.0(4.0)^{x}$ \\
\hline \multicolumn{8}{|c|}{ Alcohol (5 or more drinks) } \\
\hline$<1 /$ week & 90 & $13.6(8.3)$ & $15.7(12.8)$ & $48.7(7.8)$ & $4.8(2.5)$ & $4.6(2.3)$ & $47.8(4.0)$ \\
\hline$\geqslant 1 /$ week & 10 & $12.4(6.0)$ & $15.1(13.4)$ & $47.1(3.4)$ & $3.4(0.9)^{*}$ & $4.3(1.8)$ & $48.9(4.4)$ \\
\hline \multirow{2}{*}{\multicolumn{8}{|c|}{$\begin{array}{l}\text { Plant exposures } \\
\text { Herbicides other than triallate }\end{array}$}} \\
\hline & & & & & & & \\
\hline No & 22 & $17.7(11.1)$ & $21.4(20.6)$ & $48.6(5.0)$ & $6.0(2.4)$ & $5.5(2.2)$ & $47.4(4.0)$ \\
\hline Yes & 78 & $12.3(6.6)^{*}$ & $14.0(9.0)$ & $48.5(8.1)$ & $4.3(2.3)^{*}$ & $4.3(2.2)^{*}$ & $48.0(4.1)$ \\
\hline \multicolumn{8}{|c|}{ Occupational exposures in jobs prior to employment at the plant } \\
\hline Solvents & & & & & & & \\
\hline No & 66 & $12.6(8.4)$ & $13.8(13.4)$ & $48.1(8.3)$ & $5.0(2.7)$ & $4.8(2.5)$ & $47.6(4.2)$ \\
\hline Yes & 34 & $15.1(7.3)$ & $19.2(10.8)^{*}$ & $49.4(5.7)$ & $4.2(1.9)$ & $4.0(1.7)$ & $48.4(3.7)$ \\
\hline
\end{tabular}

${ }^{*} \mathrm{p}<0.05$, two sided $t$ test comparing mean of subjects exposed with mean of subjects unexposed to each factor.

tRisk factors for which there was no statistically significant difference between mean values of exposed and unexposed subjects, and not displayed in the table were gender, height, urinary tract infection, gastrointestinal disorder, cervical disk disorder, carpal tunnel syndrome, slipped disk, head injury, allergic conditions, recreational drugs, lead used in hobby, herbicides or insecticides used in the home, plant exposures to solvents, industrial adhesives and exposures in jobs prior to plant employment to industrial adhesives, herbicides, insecticides.

¥Sural nerve tests: PA, peak amplitude; PPA, peak-to-peak amplitude; VEL, velocity.

§Peroneal nerve tests: AA, amplitude, ankle; FNA, amplitude, fibular neck; VEL, velocity.

fracture do not appear to be biologically meaningful. Several studies of occupational groups exposed to solvents have shown reductions in sural nerve amplitude and velocity as well as peroneal nerve amplitude and velocity. ${ }^{17} 18$

\section{Neurological examinations}

The prevalence of abnormal findings on the neurological examinations was similar in the high and the no/low triallate groups, and five of the six cases in the high triallate group had a condition that was not likely to be due to occupational exposure. Three of these cases had a condition that was present before beginning employment at the plant, and two had a mild conductive type of hearing loss. Conductive hearing loss occurs as a result of conditions in the external and middle ear and not because of any damage to the nervous system. The sixth case had a sensorineural hearing loss and a unilateral Bell's palsy occurring at different points in time. Bell's palsy is the most common form of facial paralysis, and its aetiology is unknown. ${ }^{28}$ In sum, none of the cases had findings to support neurological changes observed in rats exposed to triallate.

\section{Vibration perception threshold}

Our vibrometry and neurological examination results did not indicate any association between triallate and vibration perception threshold. As noted earlier, only one subject had a marked reduction in the vibration perception threshold. The abnormality was limited to the great toe, was not accompanied by overt signs of neuropathy, and occurred in a subject in the no/low triallate group.

\section{Strengths and limitations}

Strengths of the research included the high participation and the use of all available work history information and of objective procedures for developing triallate scores. The interviews, neurological examination, and nerve conduction tests were done by research staff who were not aware of subjects' exposure, thus minimising the potential for biased 
Table 5 Vibration perception threshold test results by triallate exposure category

\begin{tabular}{|c|c|c|c|c|c|c|c|c|c|}
\hline \multirow[b]{2}{*}{ Vibration test* } & \multicolumn{3}{|c|}{ All subjects } & \multicolumn{3}{|c|}{ Hired 1976-85 } & \multicolumn{3}{|c|}{ Hired $>1985$} \\
\hline & $\begin{array}{l}\text { No/low } \\
\text { exposure }\end{array}$ & High exposure & p† & $\begin{array}{l}\text { No/low } \\
\text { exposure }\end{array}$ & High exposure & pt & $\begin{array}{l}\text { No/low } \\
\text { exposure }\end{array}$ & High exposure & pt \\
\hline \multicolumn{10}{|l|}{ Great toe } \\
\hline $\mathrm{n}$ tested & 50 & 50 & & 25 & 25 & & 25 & 25 & \\
\hline Range & $0.8-6.2$ & $0.6-7.1$ & & $0.8-6.2$ & $0.8-7.1$ & & $0.9-2.4$ & $0.6-5.5$ & \\
\hline Median & 1.7 & 1.6 & & 1.8 & 1.6 & & 1.6 & & \\
\hline Mean (SD) & $1.8(0.9)$ & $2.0(1.3)$ & 0.34 & $2.1(1.2)$ & $2.3(1.6)$ & 0.57 & $1.6(0.4)$ & $1.8(1.0)$ & 0.34 \\
\hline Mean, adjusted $\ddagger$ & 1.8 & 2.0 & 0.26 & 1.9 & 2.4 & 0.16 & 1.7 & 1.7 & 0.71 \\
\hline \multicolumn{10}{|l|}{ Finger } \\
\hline $\mathrm{n}$ tested & 50 & 50 & & 25 & 25 & & 25 & 25 & \\
\hline Range & $0.1-1.1$ & $0.3-1.4$ & & $0.1-0.9$ & $0.3-1.4$ & & $0.2-1.1$ & $0.3-1.0$ & \\
\hline Median & 0.6 & 0.6 & & 0.6 & 0.7 & & 0.6 & 0.6 & \\
\hline Mean (SD) & $0.6(0.2)$ & $0.7(0.2)$ & 0.34 & $0.6(0.2)$ & $0.7(0.3)$ & 0.13 & $0.6(0.2)$ & $0.6(0.2)$ & 0.68 \\
\hline Mean, adjusted $\neq$ & 0.6 & 0.7 & 0.32 & 0.6 & 0.7 & 0.08 & 0.6 & 0.6 & 0.36 \\
\hline
\end{tabular}

*Reported as vibration units.

TTwo sided $t$ test used to compare the unadjusted mean of the high exposure group with the unadjusted mean of the no/low exposure group; $F$ test used to compare the adjusted mean of the high exposure group with the adjusted mean of the no/low exposure group.

$\ddagger$ Adjusted for age, gender, and height using analysis of covariance.

measurement of the outcomes of interest. Analytical procedures adjusted for a number of possible confounding factors.

The cross-sectional design of the study imposed several limitations. Persistent neurological abnormalities could have been present before triallate exposure began. We addressed this possibility by determining the dates of onset of the abnormalities and by comparing these dates with plant hire dates. Employees who developed neurological problems might have left work before the study began. Reasons for leaving work, recorded in employment records, may not identify all cases of medical disability. However, plant records indicated that only four of 414 non-retired terminees left work because of medical disabilities, three of which were non-neurological, and one of which was a non-occupational neurological injury. Death certificates, available for 37 of the 39 decedents in the study base, indicated that only one death was due to a neurological condition, an acute seizure disorder in an employee whose triallate exposure score of 0 . Other limitations included low power to detect differences between the triallate groups in neurological outcomes other than nerve conduction results, lack of quantitative exposure estimates for triallate and other agents, and lack of information on several potential risk factors such as certain ergonomic habits.

\section{Conclusion}

This study evaluated the relation between exposure to triallate in a manufacturing setting and neurological outcomes, including peripheral sensory and motor nervous system function, as measured by nerve conduction tests; neurological abnormalities, as determined by clinical examination; and vibration sensation, as assessed by vibrometry. The results were consistent with the absence of an association between triallate and these measures of neurological function.

\section{ACKNOWLEDGEMENTS}

The authors gratefully acknowledge the enthusiasm and cooperation of plant employees. The authors also thank Drs John Acquavella, Daniel Goldstein, and Abby Li for their efforts to facilitate the project.

\section{Authors' affiliations \\ N Sathiakumar, E Delzell, P A MacLennan, H Cheng, S L Myers, Department of Epidemiology, School of Public Health, University of Alabama at Birmingham, Alabama, USA \\ M Anne, Monsanto Company, USA \\ N L Rosenberg, Deceased}

Sponsor: Monsanto Company

\section{REFERENCES}

1 Li AA, Branch DK, Thake DC, et al. Subchronic neurotoxicity study of triallate in Sprague-Dawley rats. Unpublished Monsanto Report MSL-13157, 1993.

2 Li AA, Thake DC, Branch DK, et al. Acute neurotoxicity study of triallate in Sprague-Dawley rats. Unpublished Monsanto Report MSL-12918, 8 July, 1993.

3 Li AA, Thake DC, Branch DK, et al. Assessment of brain pathology in SpragueDawley rats exposed to triallate for five weeks in the diet. Unpublished Monsanto Report MSL-15749, November, 1998.

4 Ireland B, Acquavella JF, Farrell T, et al. Evaluation of ocular health among alachlor manufacturing workers. J Occup Med 1994;36:738-42.

5 Leet T, Acquavella J, Lynch $C$, et al. Cancer incidence among alachlor manufacturing workers. Am J Ind Med 1996;30:300-6.

6 Acquavella JF, Riordan SG, Anne M, et al. Evaluation of mortality and cancer incidence among alachlor manufacturing workers. Environ Health Perspect 1996; 104:728-33.

7 Oh SJ. Clinical electromyography: nerve conduction studies, 2nd edn. Baltimore: Williams \& Wilkins, 1993.

8 Kimura J. Electrodiagnosis in diseases of nerves and muscle: principles and practice, 2nd edn. Philadelphia: F. A. Davis Company, 1989.

9 Dyck PJ, Thomas PK, Griffin JW, et al. Peripheral neuropathy, 3rd edn Philadelphia: W. B. Saunders Company, 1993.

10 Arezzo IC, Schaumburg HH, Laudadio C. The vibratron: a simple device for quantitative evaluation of tactile/vibratory sense. Neurology 1985;35(suppl 1):169.

11 Bleecker ML. Quantifying sensory loss in peripheral neuropathies. Neurobehav Toxicol Teratol 1985;7:305-8.

12 Kokmen E, Offord K. Short test of mental status: description and preliminary results. Mayo Clinic Proc 1987;62:281-6.

13 Kokmen E, Smith GE, Petersen RC, et al. The short test of mental status. Arch Neurol 1991;48:725-8.

14 Calvert GM, Mueller CA, Fajen JM, et al. Health effects associated with sulfuryl fluoride and methyl bromide exposure among structural fumigation workers. Am J Public Health 1998;88:1774-80.

15 Ellingsen DG, Moreland T, Andersen A, et al. Relation between exposure related indices and neurological and neurophysiological effects in workers previously exposed to mercury vapour. $\mathrm{Br} J$ Ind Med 1993;50:736-44.

16 Engel LS, Keifer MC, Checkoway H, et al. Neurophysiological function in farm workers exposed to organophosphate pesticides. Arch Environ Health 1998;53:7-14.

17 Huang C-C, Shih T-S, Cheng S-Y, et al. $n$-Hexane polyneuropathy in a ballmanufacturing factory. J Occup Med 1991;33:139-42.

18 Moen BE, Riise T, Todnem K, et al. Seamen exposed to organic solvents. A cross-sectional study with special reference to the nervous system. Acta Neurol Scand 1988;78:123-35.

19 Nasterlack M, Dietz MC, Frank KH, et al. A multidisciplinary cross-sectional study on solvent-related health effects in painters compared with construction workers. Int Arch Occup Environ Health 1999;72:205-14.

20 Ruiiten MWMM, Salle HJA, Verberk MM, et al. Effect of chronic mixed pesticide exposure on peripheral and autonomic nerve function. Arch Environ Health 1994;49:188-94.

21 Sweeney MH, Fingerhut MA, Arezzo JC, et al. Peripheral neuropathy after occupational exposure to 2,3,7,8-tetrachlorodibenzo-p-dioxin (TCDD). Am J Ind Med 1993;23:845-58.

22 Triebig G, Claus D, Csuzda I, et al. Cross-sectional epidemiological study on neurotoxicity of solvents in paints and lacquers. Int Arch Occup Environ Health 1988;60:233-41. 
23 Viaene MK, Roels HA, Leenders J, et al. Cadmium: a possible etiological factor in peripheral polyneuropathy. Neurotoxicology 1999;20:7-16.

24 Buschbacher RM. Body mass index effect on common nerve conduction study measurements. Muscle Nerve 1998;21:1398-404.

25 Berciano J, Combarros O, Calleja J, et al. The application of

nerve conduction and clinical studies to genetic counseling in hereditary motor and sensory neuropathy type I. Muscle Nerve

$1989 ; 12: 302-6$.
26 Dyck PJ, Litchy WJ, Lehman KA, et al. Variables influencing neuropathic endpoints: the Rochester diabetic neuropathy study of healthy subjects. Neurology 1995;45:1115-21.

27 Husstedt IW, Grotemeyer KH, Schlake HP, et al. Dysfunction of the sural nerve in cigarette smokers [in German]. EEG EMG Z Elektroenzephalogr Elektromyogr Verwandte Geb 1988;19:161-4.

28 Wilson JD, Braunwald E, Isselbacher KJ, et al, eds. Harrison's principles of internal medicine, 12th edn. USA: McGraw-Hill, Inc., 1991. 